\title{
Blood flow into ulcer-like projection of a type B aortic dissection visualized with computational fluid dynamics
}

\author{
Yasunori Iida, MD, PhD, Akihiro Yoshitake, MD, PhD, and Hideyuki Shimizu, MD, PhD
}

\footnotetext{
From the Department of Cardiovascular Surgery, Keio University, Tokyo, Japan. Disclosures: Authors have nothing to disclose with regard to commercial support.

Received for publication March 9, 2017; accepted for publication April 18, 2017; available ahead of print May 26, 2017.

Address for reprints: Yasunori Iida, MD, PhD, Department of Cardiovascular Surgery, Keio University, 35 Shinanomachi, Shinjuku-ku, Tokyo 160-8582, Japan (E-mail: hhttss1130@gmail.com).

J Thorac Cardiovasc Surg 2017;154:1217-8

$0022-5223 / \$ 36.00$

Copyright (C) 2017 by The American Association for Thoracic Surgery

http://dx.doi.org/10.1016/j.jtcvs.2017.04.040
}

A 65-year-old man who had a diagnosis of acute type B aortic dissection with ulcer-like projection (ULP) was admitted to our institution. Computed tomographic angiography (CTA) on admission showed the ULP in the descending thoracic aorta (Figure 1, left). The patient received conservative treatment with antihypertensive medication and was discharged 14 days after the onset of symptoms. During the follow-up, we performed repeated CTA 9 months after the occurrence of the aortic dissection. The follow-up CTA indicated ULP dilatation in the descending thoracic aorta (Figure 1, right). In an attempt to examine how much blood was flowing into the ULP lesion at the patient's first admission, we applied the theory of computational fluid dynamics to the initial CTA data. We quantified the amount of blood flow entering the ULP lesion and calculated the proportion of the inflow rate into the ULP lesion. The results (Figures 2 and 3 ) showed that the vortex flow into the lesion could be visualized (Figure 2) and that the inflow rate into the ULP lesion was $110 \mathrm{~mL} / \mathrm{min}$ (Figure 3). To our knowledge, this is the first time that the presence of persistent vortex blood flow into the ULP lesion has been visualized and that the amount of blood

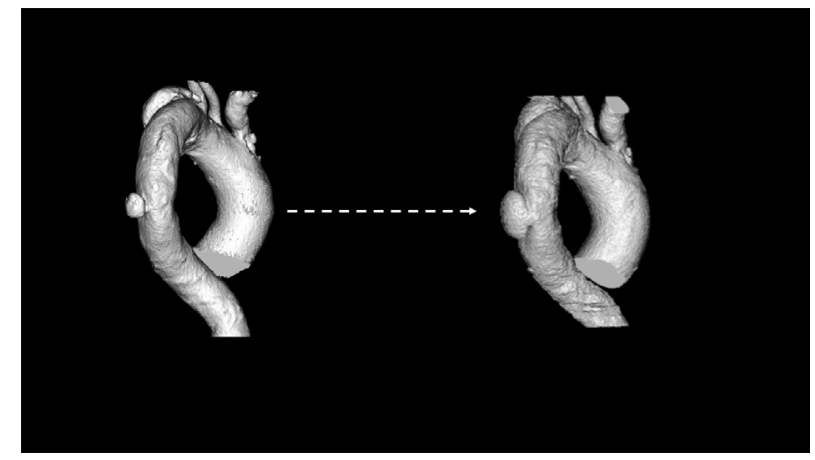

FIGURE 1. Computed tomographic angiography on admission showed an ulcer-like projection in the descending thoracic aorta (left). Follow-up computed tomographic angiography indicated ulcer-like projection dilatation in the descending thoracic aorta (right).

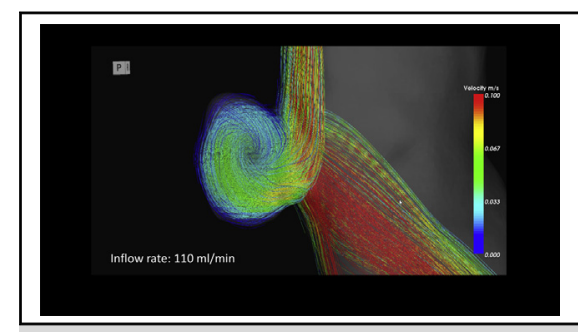

Vortex flow into the ulcer-like projection is visualized by computational fluid dynamics.

\section{Central Message}

We visualized the vortex flow into the ULP lesion and determined its inflow rate by means of CFD. This is the first time that persistent vortex blood flow into such a lesion has been visualized.

See Editorial Commentary page 1219.

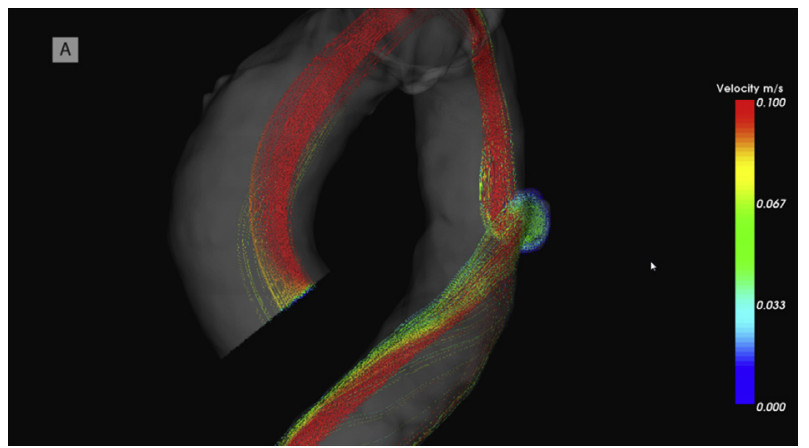

FIGURE 2. Results of computational fluid dynamic calculations from computed tomographic angiographic data allow the vortex flow into the lesion to be visualized.

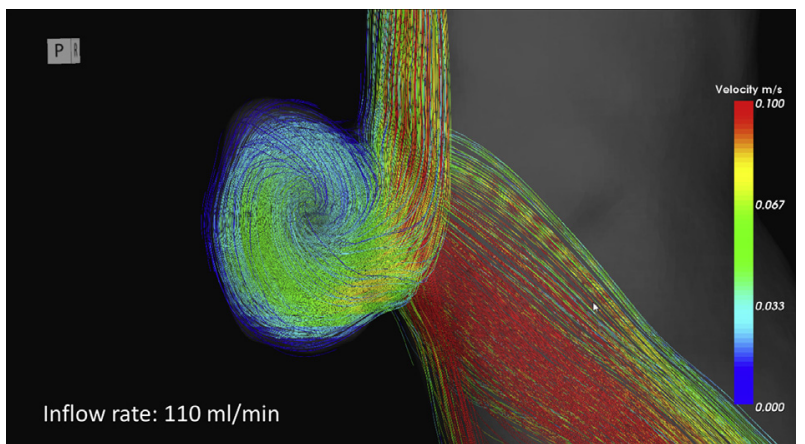

FIGURE 3. Results of computational fluid dynamic calculations from computed tomographic angiographic data show that the inflow rate into the ulcer-like projection lesion was $110 \mathrm{~mL} / \mathrm{min}$. 
flow has been calculated. Accumulation of additional experimental data is needed to elucidate the many patterns of ULP lesion hemodynamics in aortic dissection by means of computational fluid dynamics. This information will enable the efficient performance of thoracic endovascular aortic repair when a patient who has an acute type B aortic dissection with ULP is admitted.

The authors thank Takanobu Yagi, Dr Eng, EBM Corporation, for examining and analyzing the data. 